\title{
UAV PHOTOGRAMMETRY FOR RESILIENCE MANAGEMENT IN RECONSTRUCTION PLAN OF URBAN HISTORICAL CENTRES AFTER SEISMIC EVENTS. A CASE STUDY
}

\author{
M. Alicandro ${ }^{1}$, M. Rotilio ${ }^{1 *}$ \\ ${ }^{1}$ DICEAA, Civil, Construction-Architectural and Environmental Engineering Department, 67100 L'Aquila, Italy- (maria.alicandro, \\ marianna.rotilio)@univaq.it
}

KEY WORDS: UAV Photogrammetry, Reconstruction plan, Rehabilitation historical centres, Building sites

\begin{abstract}
:
In the last decades, the UAV photogrammetry has been widely employed to obtain a complete and metric survey in different fields, especially when high resolution, speed of execution and safety are required. It is widely used in the construction sector and an interesting research field is their use to support the historical centres urban renewal projects, especially in post-earthquake reconstruction. In fact, the establishment of a construction site involves several intrinsic criticalities linked to the nature of the context, and especially in a post-earthquake scenario, additional problems arise beyond these critical elements. These conditions affect the preservation of historical centres, planned conservation, risk and resilience management. For this reason, it is necessary to develop innovative methodologies and strategy to plan interventions and to manage the construction sites in the historical centre after an earthquake.

The use of UAV photogrammetry is a tool to support this activity in this field because it allows obtaining a complete and a highresolution geometric survey of the areas to be reconstructed in a fast way and especially in total safety for the operators. For this reason, this study aims to illustrate a methodology that, starting from a series of preliminary surveys, supports the development of the program of reconstruction of a historic urban centre hit by an earthquake event. The aim of this research is to prevent problems, interferences and criticalities in order to increase the safety and rationality of the entire reconstruction process.
\end{abstract}

\section{INTRODUCTION}

UAV (Unmanned Aerial Vehicle) photogrammetry has known a growing variety of applications in different scientific disciplines (Sauerbier et al. 2010). In the last decades, the UAV photogrammetry has been widely employed to obtain a complete and metric survey in different fields, especially when high resolution, speed of execution and safety are required. The photogrammetric process can deliver several types of output to export 3D models and other qualitative information of the buildings, with an accuracy to centimetre-level. These technologies are widely used in the construction sector and an interesting application field is related to the architectural and cultural heritage. Themistocleous et al. (2015) claim that UAVs are used for cultural detection of historical sites due to their convenience, reliability and ease of use. Brutto et al. (2014) underline that the UAVs have allowed to overcome the difficulties linked he survey of large areas of entire urban or archaeological centres. A recent field of research concerning the use of these technologies is that related to post-disaster interventions and some authors have already published some results. Dominici et al. (2016) believe that UAV photogrammetry is an excellent data acquisition platform for metric surveys of damage in areas inaccessible or unsafe for human beings. Gagliolo et al. (2017) explain that UAV photogrammetry allows to obtain good results in terms of speed, economy, precision and accuracy, while ensuring the safety of operators in critical situations. They have also discussed a case study carried out in Italy. Also Achille et al. (2015) have illustrated the results of a verified research on a case study in Italy, the Santa Barbara Church and its bell tower in Mantua damaged by the 2012 earthquake. The same goes for Ballarin et al. (2013) who have illustrated the first results of the analysis developed on the church of San Geminiano in San Felice sul Panaro (Modena) also damaged by the 2012 earthquake. Xu et al. (2014) instead highlighted the importance of the UAS (Unmanned Aircraft System) in the immediate post-disaster to get the first information useful to organize the rescue and estimate the damage (Meyer et al., 2015). On the contrary Restas (2015) has highlighted, that depending on the type of disaster, it is necessary to quickly obtain different types of information. For this purpose, the use of UAV is an excellent strategy.

It is therefore evident that the use of these technologies is very useful for the management of a disastrous event but, in fact, they are extremely useful also to support the historical centres urban renewal projects, especially in post-earthquake reconstruction (Dominici et Al. 2017, 2018).

The urban fabric of any settlement can be interpreted by analyzing the built fabric and the open spaces where one represents the negative of the other. In particular, historic villages are generally characterized by very dense urban fabrics, where the built and open spaces blend together creating a complex and indissoluble relationship. This is because the built fabric is the result of different types of aggregation of the elementary cell, whose growth has occurred until saturation according to the territorial morphology and according to generating axes. For this reason, often the open spaces are made up of slabs, areas of limited size.

The minor historical centres are therefore the result of material culture, of the knowledge acquired daily by the experience of our predecessors, handed down from father to son and preserved as a precious treasure, a testimony of value. Therefore, due to its nature, the construction of a building site in a minor centre is not a simple activity, because of a complex context. The establishment of a rehabilitation construction site

\footnotetext{
* Corresponding author
} 
involves several intrinsic criticalities linked to the nature of the context, such as quality and size, sometimes very limited, of the available space, presence of adjoining buildings, presence of inhabitants and tourists, difficulty in storing, covering and moving people, materials and vehicles, quality and complex interdependence of the various operational phases (De Berardinis et al. 2018, Lucarelli et al. 2018, Rotilio et al. 2018). In a post-earthquake scenario, additional problems arise beyond these critical elements due to the presence of damaged buildings, the crucial importance of temporary works, safety and service and the presence of multiple construction sites at the same time. These conditions affect the preservation of historical centres, planned conservation, risk and resilience management. In fact, in these cases, planners and designers have to optimize the space management in the reconstruction site plan. A big challenge is to find appropriate space for materials and ruins storage, for the management of ancillary services and the coordination of the simultaneous presence of trucks in narrow streets (typical of historic centres) and with limited access.

For this reason, it is necessary to develop innovative methodologies and strategies to plan interventions and to manage the construction sites in the historical centre after an earthquake. Above all, a rational planning is necessary, also to manage the auxiliary factors, i.e. welfare facilities, service areas and equipment.

The use of UAV photogrammetry is a tool to support this activity in this field because it allows obtaining a complete and a high-resolution geometric survey of the areas to be reconstructed in a fast way and especially in total safety for the operators. The outputs derived from the photogrammetry, such as 3D models, Orthomosaics, Digital Elevation Model (DEM) and point clouds are useful to analyse the current situation of the investigated area and to plan the operational steps for all construction sites in order to guarantee a full coordination among themselves. For this reason, this study aims to illustrate a methodology that, starting from a series of preliminary surveys, supports the development of the program of reconstruction of a historic urban centre hit by an earthquake event. The aim of this research is to prevent problems, interferences and criticalities in order to increase the safety and rationality of the entire reconstruction process.

\section{RESEARCH AND METHODOLOGY}

This research has originated from some considerations born from the observation of the reconstruction of the historical centres located in Italy, in the Abruzzo Region, particularly in the Province of L'Aquila, hit by the 2009 earthquake. The process of reconstruction of the historical centre was based on the so-called Reconstruction Plans whose contents and objectives were set in the Abruzzo Decree n. 39.2009, converted into Law no. 77.2009. These plans had to include the methods of connecting the various areas, to identify the sectors of intervention and the primary and secondary urbanization works to be carried out and to define, in a coordinated manner, the planning and execution of public and private works. Actually, in many cases, the planning activity hasn't taken into account the interferences, the real availability of the spaces, the exact chronology of the work to be implemented, the actual level of damage of the buildings to be recovered, the timing of the priority actions. Therefore, the time scheduling of the works annexed to the plan has undergone significant delays. In summary, the reconstruction activity hasn't often complied with the programming specified in the documents giving rise to complex problems, interference, irrationality and delays.
In light of these critical issues, a methodology has been developed that, based on detailed analysis carried out also thanks to the use of UAV technologies, has led to the development of a versatile intervention plan, easily upgradable and closely linked to the context.

The UAV photogrammetry permits to extract several geometrical information starting from the acquisition of two or more images from different point of views and with an adequate overlap between images. The methodology of UAV photogrammetry are based on the approach of digital photogrammetry techniques (Arias-Pérez et al., 2012; Triggs et al., 1999, Kraus, 1994,) and the principal steps are summarized in Figure 1 and discussed in the following section.

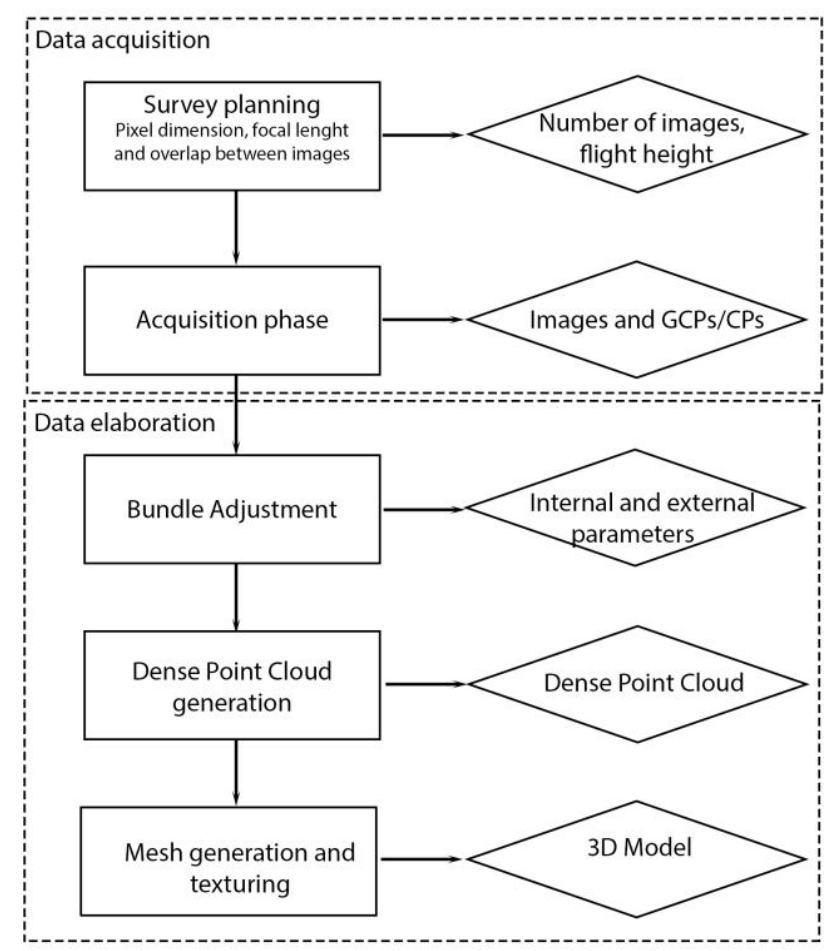

Figure 1 . The methodology of UAV photogrammetry

In particular, thanks to UAV photogrammetry, it has been possible to obtain the following data:

\section{Survey of the damage}

2. Location and quantification of rubble

3. Analysis and sizing of public and private open spaces

4. Survey and identification of traffic and access, both drivable and pedestrian

5. Roadway analysis and sizing

6. Volumetric reconstruction of the entire urban fabric.

These documents have been obtained in limited period time and above all in conditions of complete security for the operators. Once the outputs have been extrapolated, a synthesis process has been done that has led to the identification of "Planning lines" and of the "Autonomous areas" of construction site set-up in relation to which the specific planning strategies have been elaborated. For each autonomous zone, interference has been resolved and accesses, road conditions, service areas and equipment location have been established.

Once all critical issues were resolved, it was possible to define the work phases and the related 
timeline. This programming allows to carry out the activities without any interference and above all it allows the operators to easily reach and organize all the buildings of the historic centre without any interference, also in order to guarantee the safety of the operators.

This methodology has been applied to the case study of Villa Sant'Angelo, a small historical village in the Province of L'Aquila.

\section{CASE STUDY AND RESULTS}

\subsection{The historical village of Villa Sant'Angelo}

The minor centre of Villa Sant'Angelo is located in Italy, in the province of L'Aquila, and it is an ancient village in the Aterno Valley.

Following the 2009 earthquake, an important part of this village collapsed, so most of the buildings in the area of the historical centre have been classified as condemned (Figure 2).

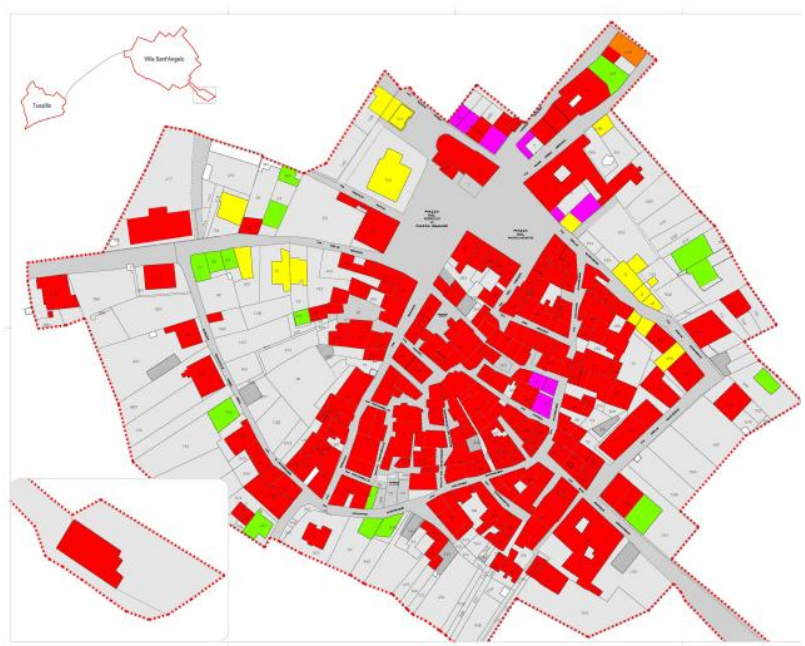

Figure 2. Classification of buildings in the Reconstruction Plan. In red the condemned buildings

For this reason, due to the difficult visibility conditions of the historical centre and areas of interest, it was necessary to perform a metric survey, in order to study the real conditions of the not accessible areas due to the presence of collapses, ruins and rubble in the investigated area. As already argued, this analysis was not carried out soon after the earthquake event but at the time of the reconstruction of the village.

\subsection{UAV photogrammetry survey}

The UAV photogrammetry survey has concerned an area of about $0.05 \mathrm{Km}^{\wedge} 2$. The survey has been implemented using an esa-copter Micro-UAV Flynovex equipped with Sony alpha 6000 camera (Figure 3) with a pixel size of $4 \mu \mathrm{m}$ and focal length of $16 \mathrm{~mm}$ (Table 1). The flight altitude was set to $50 \mathrm{~m}$ to obtain a 1 centimetre of GSD and considering the presence of two cranes. Two flight were planned in opposite direction with high overlapping (90\% for the longitudinal side and $80 \%$ for the transversal side) to avoid problems of occlusion.

During the survey phase, 400 images were acquired and 12 Ground Control Points/Check Points (GCPs/CPs) were measured with a GNSS receiver in NRTK mode.
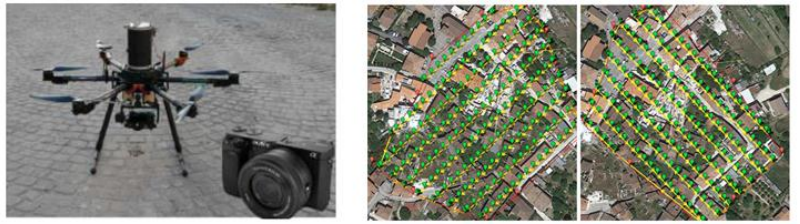

Figure 3. Flight Planning

The set of images and the GCPs/CPs were elaborated with Agisoft Photoscan Professional software (Version 1.2.4, Agisoft LLC, www.agisoft.com), a software based on "Structure For Motion - SFM" and "MultiView Stereo - MVS" algorithms to reconstruct the georeferenced $3 \mathrm{D}$ model. Table 1 shown the parameters in the main steps of the elaboration: alignment phase, dense point cloud generation, 3D model elaboration phase.

\begin{tabular}{|c|c|c|c|}
\hline \multirow{2}{*}{\multicolumn{3}{|c|}{ Type of UAV }} & Mini-UAV \\
\hline & & & Hexa-copter \\
\hline \multirow{7}{*}{$\begin{array}{l}\text { Optical } \\
\text { Sensor }\end{array}$} & \multicolumn{2}{|c|}{ Camera } & Sony alpha 6000 \\
\hline & \multicolumn{2}{|c|}{ Resolution } & $24 M P$ \\
\hline & \multicolumn{2}{|c|}{ Focal length } & $16 \mathrm{~mm}$ \\
\hline & \multirow{2}{*}{$\begin{array}{c}\text { Sensor } \\
\text { dimensions }\end{array}$} & width & $24 \mathrm{~mm}$ \\
\hline & & height & $16 \mathrm{~mm}$ \\
\hline & \multicolumn{2}{|c|}{ Pixel dimension } & $4.3 \mu m$ \\
\hline & \multicolumn{2}{|c|}{ Weight } & $345 g$ \\
\hline Case study & \multicolumn{3}{|c|}{$\begin{array}{c}\text { Villa Sant'Angelo }(A Q) \text { - Historical } \\
\text { Centre }\end{array}$} \\
\hline Area of survey & \multicolumn{3}{|c|}{$\approx 0.05 \mathrm{~km}^{\wedge} 2$} \\
\hline \multicolumn{2}{|l|}{ Flight altitude } & \multicolumn{2}{|c|}{$50 \mathrm{~m}$} \\
\hline \multicolumn{3}{|c|}{ Ground Sample Distance (GSD) } & $\approx 1,22 \mathrm{~cm}$ \\
\hline \multirow{2}{*}{\multicolumn{2}{|c|}{ Overlapping of photograms }} & Forward & $90 \%$ \\
\hline & & Side lap & $80 \%$ \\
\hline \multicolumn{4}{|c|}{ Number of images 400} \\
\hline GCPs/CPs & \multicolumn{3}{|c|}{12 measured with GNSS un RTK mode } \\
\hline \multicolumn{4}{|c|}{ Elaboration data } \\
\hline \multicolumn{2}{|c|}{ Alignment parameter } & \multicolumn{2}{|c|}{ High accuracy } \\
\hline \multicolumn{2}{|c|}{ Dense Point Cloud } & \multicolumn{2}{|c|}{ High quality } \\
\hline \multicolumn{2}{|c|}{$3 D$ model } & Surface & ype Height field \\
\hline \multicolumn{2}{|c|}{ DEM } & & $2 \mathrm{~cm} / \mathrm{pix}$ \\
\hline
\end{tabular}

Table 1. Used hardware component and general data of the survey and photogrammetry elaboration

The alignment phase estimate internal (focal length, position of the principal point $-\mathrm{x}_{\mathrm{p}}$ and $\mathrm{y}_{\mathrm{p}}$ - and the distortion parameters of the sensor) and external (location and orientation of the images during the acquisition $-\mathrm{X}_{0}, \mathrm{Y}_{0}, \mathrm{Z}_{0}, \omega, \varphi$ and $\gamma$ ) camera orientation parameters (Barazzetti, 2009; Nex et al., 2014). The parameter estimation achieves in three steps:

1.Automatic extraction of key-points (Ahmadabadian et al., 2013; Bay et al., 2008; Lowe, 2004);

2.Image matching to identify tie-points (Remondino, 2006);

3.Bundle adjustment to estimate the camera orientation parameters (Triggs et al., 1999).

During this phase, GCPs and CPs were manually detected on images and were used in the bundle adjustment to estimate the final values of internal and external parameters. In this case Table 2, we use 8 GCPs to solve the bundle adjustment, while the $4 \mathrm{CPs}$ were used to validate the results of the bundle adjustment. 


\begin{tabular}{|c|c|c|}
\hline GCPS & $\begin{array}{c}\text { RMSE } \\
(\boldsymbol{m})\end{array}$ & $\boldsymbol{R M S E}($ pix) \\
\hline 8 & 0.08 & 1.19 \\
\hline CPS & $\begin{array}{c}\text { RMSE } \\
(\boldsymbol{m})\end{array}$ & $\boldsymbol{R M S E}($ pix $)$ \\
\hline 4 & 0.09 & 1.19 \\
\hline
\end{tabular}

Table 2. Root Mean Square Error (RMSE) of GCPs and CPs

Finally, a dense point clouds was performed in high quality (Furukawa et al., 2015; Furukawa et al., 2010; Harwin et al., 2012).

Once obtained the geometry of the survey, a mesh was built with MVS procedure (Koci et al., 2017). The mesh was generate with "height field" mode because we were not interested to reconstruction of the façade details and to speed up the elaboration. After all, a DEM and the orthomosaic have been extract (Figure 4).

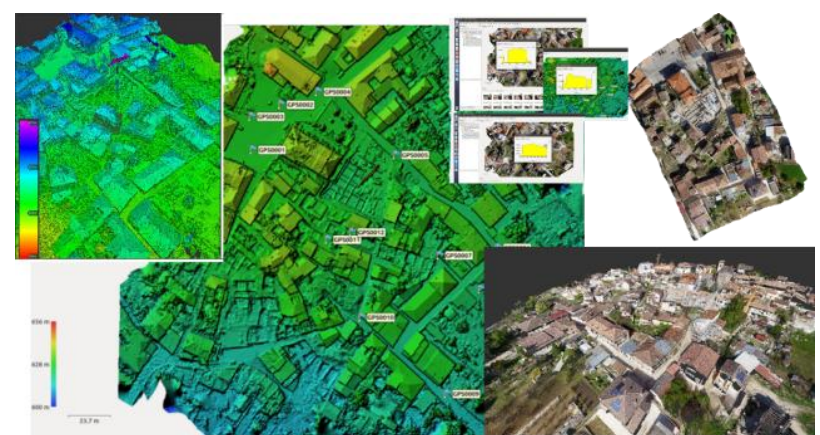

Figure 4. Point Cloud, DEM and orthomosaic of Villa Sant'Angelo (AQ)

Starting from these outputs, an assessment of the current situation of the area has been performed. It was possible to extract the information relative to the profile of buildings, the areas covered by rubble, the accessible streets and the cranes. This information has been collected and shown in Figure 5. Several other information are extracted relative to the open space and the active construction sites are outlined.

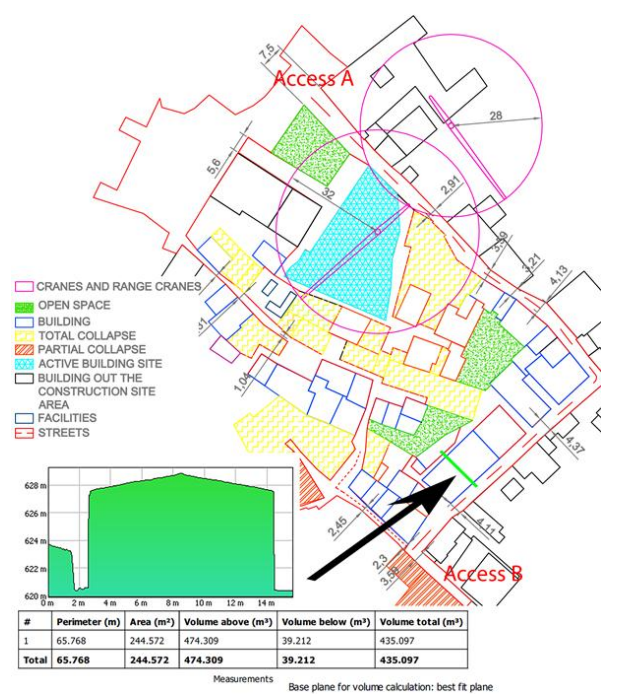

Figure 5. Criticality summary from UAV output

\subsection{Summary of the critical issues}

The UAV photogrammetry survey has highlighted that the temporal and executive reconstruction planning of the historic centre of Villa Sant'Angelo, as planned in the Reconstruction Plan, was burdened by numerous critical issues. In fact, from the point of view of access to the historic village, the date on which Figure 6 was drafted, showed that the only viable access was the one referred to in the letter "A".

On the contrary, the "B" was not accessible because of the danger of collapse of the historic building not yet secured. A similar situation for the "C" access, reachable only partially due to the risk of collapse of the neighboring buildings and in any case of limited size. Moreover, from the point of view of the planning of the works some criticalities and inconsistencies have been highlighted. In particular:

1. the building aggregates identified with the numbers "13" and "30" have undergone reconstruction works and are now habitable. However, they are surrounded by buildings to be restored. Moreover, they will be unreachable when the construction works of the building aggregates "12" and "28" start;

2 . the building aggregates " 22 ", "17", "14", "16", “18", " 09 ", " $10 "$, " 11 " e " 15 " cannot be reached by the work-site vehicles.

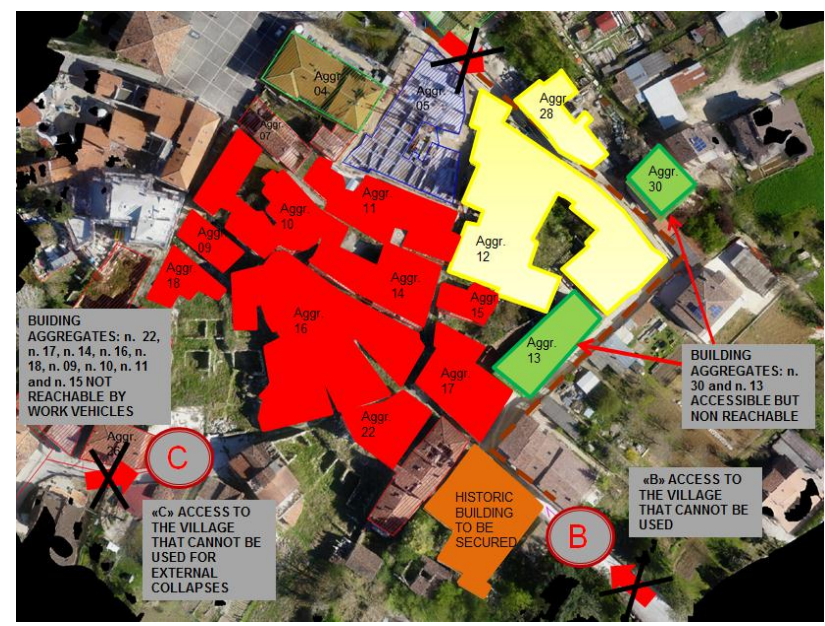

Figure 6. Analysis of the critical issues

\subsection{The intervention strategy}

Thanks to the relevant analysis carried out and in light of the critical issues encountered, the so-called "Planning lines" have been identified. Thereby, the building aggregates in which the urban fabric of the historical centre was divided, have been organized into two areas of autonomous construction site, each equipped with independent welfare facilities, service areas and equipment (Figure 7).
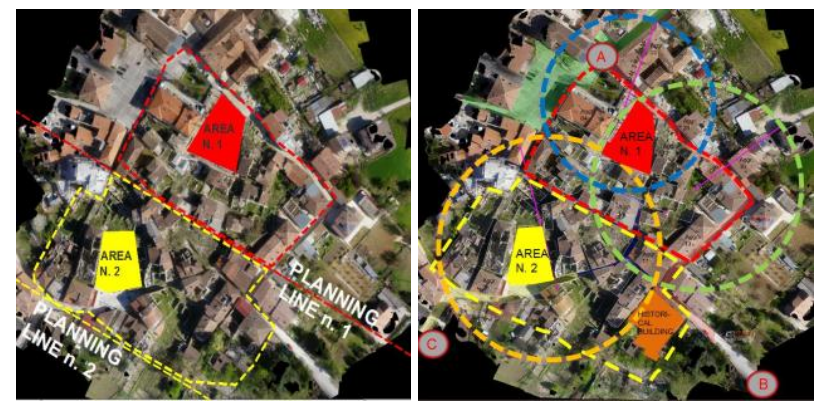

Figure 7. Each autonomous area is equipped with independent welfare facilities, service areas and equipment. On the right side the study of the cranes position 


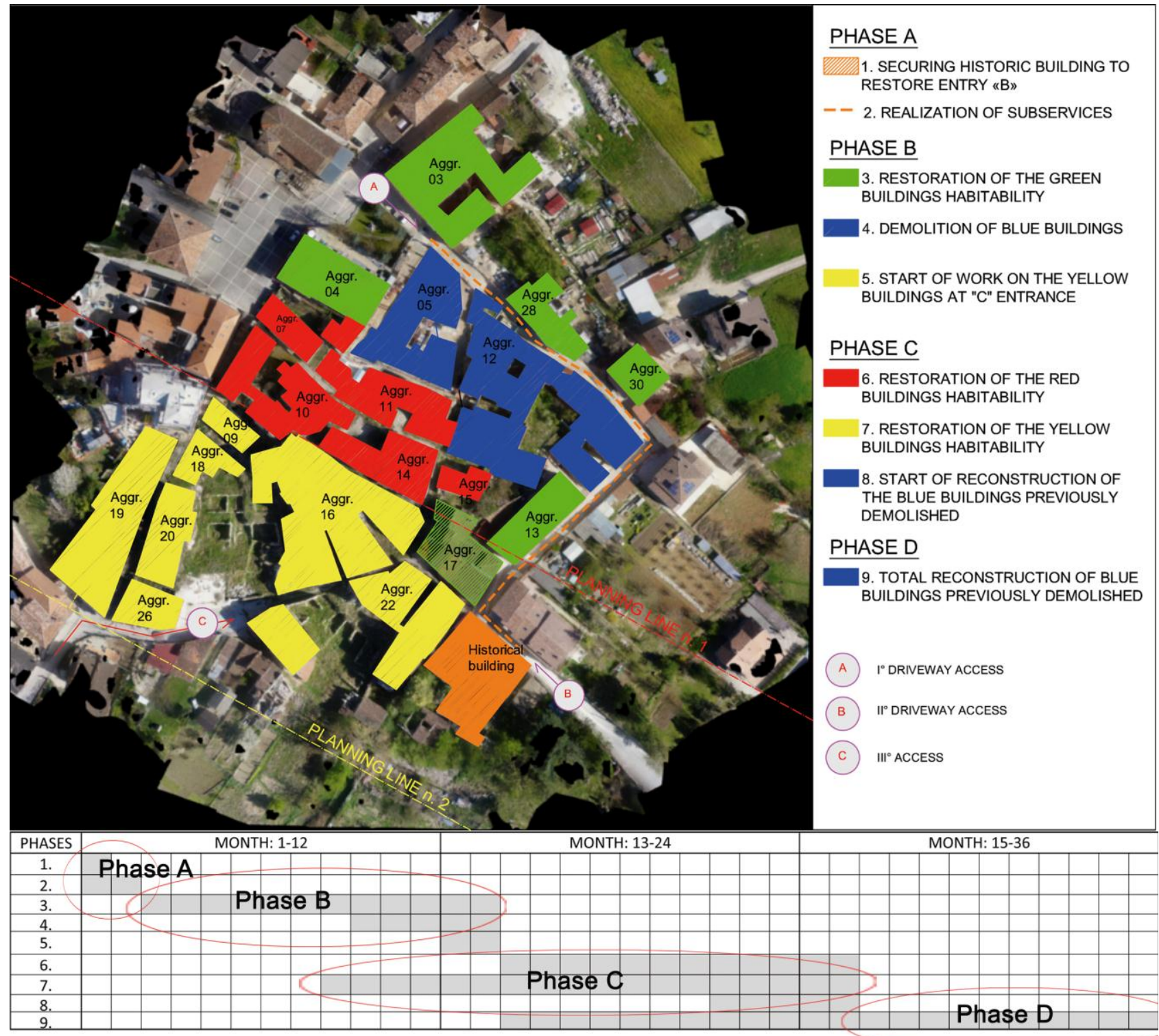

Figure 8: The reconstruction plan of Villa Sant'Angelo. Phases and time table

As for the access, the two homogeneous areas will be served by the already mentioned three accesses:

1. A access/entrance: serving the buildings that belong to the Planning Line 1;

2. B access/entrance: serving the buildings that belong to the Planning Line 1, both for single buildings and for the historic building;

3. C access/entrance: serving the buildings that belong to the Planning Line 2.

The crane installation too has been analyzed with a view to rationalization. Starting from the Figure 5, in which it is possible to see that one crane has been yet installed, another two will have to be provided to serve all the building aggregates.

Their installation and dismantling follows the planning referred to in Figure 8.

As shown in Figure 8, the reconstruction works have been programmed in a period of thirty-six months, organized into four macro-phases, and a total of nine sub-steps of variable duration.
In particular, the A "macro-phase" consists of two preliminary steps: securing the historic buildings to restore the B access and the construction of underground utility services.

After, it is possible to implement the restoration of the green buildings habitability, the demolition of the blue ones and the start of work of the yellow buildings at " $\mathrm{C}$ " access.

In the subsequent macro-phases, the works proceed with the restoration of the red and yellow buildings habitability and with the reconstruction of the previously demolished blue buildings. The "A", "B", "C", "D" macro-phases last 2, 12, 18, 21 months respectively.

\section{CONCLUSIONS}

The briefly illustrated methodology has shown that UAV photogrammetry can be successfully used to support the urban planning and reconstruction of a historical centre with multiple construction sites and building aggregates. In particular, it was possible to highlight some real criticalities did not taken into account in the Reconstruction Plans and to project a detailed and versatile plan of intervention, closely linked to the context. The possibility to have a high resolution and metric survey of the building-sites area permitted to analyse several factors (open space, road network and street width, etc.,) useful to define 
areas of autonomous construction site and to optimize the work phases during the reconstruction process.

The research confirmed that the UAV photogrammetry could be help to inspect the real situation in a post-earthquake scenario in order to planning the reconstruction phases. In the future the authors will monitor the single macro-phases to control the respect of the safety condition, to confirm the realization time and to improve the management of the interference.

\section{ACKNOWLEDGEMENTS}

M.R. defined the structure and organization of the article and supervised it. M.A. and M.R. wrote the article in an equal manner and elaborated also the figures (except Figure n. 2 that belongs to the Reconstruction Plan of Villa Sant'Angelo).

The authors names are in an alphabetical order.

The research was carried out by the authors together with Prof. Donatella Dominici and Prof. Pierluigi De Berardinis who directed and coordinated it as Scientific Supervisors.

\section{REFERENCES}

Achille, C., Adami, A., Chiarini, S., Cremonesi, S., Fassi, F., Fregonese, L., Taffurelli, L., 2015. UAV-based photogrammetry and integrated technologies for architectural applicationsMethodological strategies for the after-quake survey of vertical structures in Mantua (Italy). Sensors 15(7), pp. 15520-15539.

Ahmadabadian, A.H., Robson, S., Boehm, J., Shortis, M., Wenzel, K., Fritsch, D., 2013. A comparison of dense matching algorithms for scaled surface reconstruction using stereo camera rigs. ISPRS Journal of Photogrammetry and Remote Sensing 78, 157-167.

Arias-Pérez, B., Hernández-López, D., González-Aguilera, D., Gómez-Lahoz, J., 2012. Assessment of Stereoscopic PrecisionFilm to Digital Photogrammetric Cameras. INTECH Open Access Publisher.

Ballarin, M., Buttolo, V., Guerra, F., Vernier, P., 2013. Integrated surveying techniques for sensitive areas: San Felice sul Panaro. ISPRS Annals of the Photogrammetry, Remote Sensing and Spatial Information Sciences 5, W1.

Barazzetti, L., Remondino, F., \& Scaioni, M., 2009. Combined use of photogrammetric and computer vision techniques for fully automated and accurate 3D modeling of terrestrial objects. In Videometrics, Range Imaging, and Applications $X$ (Vol. 7447 , p. $74470 \mathrm{M})$. International Society for Optics and Photonics.

Bay, H., Ess, A., Tuytelaars, T., Van Gool, L., 2008. Speededup robust features (SURF). Computer vision and image understanding 110, 346-359.

Dominici, D., Alicandro, M., Rosciano, E., \& Massimi, V., 2017. Multiscale documentation and monitoring of L'Aquila historical centre using UAV photogrammetry. International Archives of the Photogrammetry, Remote Sensing \& Spatial Information Sciences, 42.

Dominici, D., De Berardinis, P., Alicandro, M., \& Rotilio, M., 2018. Photogrammetry from UAV in the recovery interventions: from the pre-planning phase to the construction site. GEOmedia, 22(1), 6-10. Available: <http://mediageo.it/ojs/index.php/GEOmedia/article/view/1518/ 1378> Last access: 02 gen. 2019
De Berardinis P., Di Giovanni G., Laurini E., Rotilio M., Progettare l'organizzazione del cantiere di recupero nell'ambito della ricostruzione post sismica a L'Aquila, VI Edizione Convegno ReUso, Messina 11-12-13 Ottobre 2018. Gangemi Editore, Roma, ISBN: 978-88-492-3659-0

Furukawa, Y., \& Hernández, C., 2015. Multi-view stereo: A tutorial. Foundations and Trends® in Computer Graphics and Vision, 9(1-2), 1-148.

Furukawa, Y., Ponce, J., 2010. Accurate, dense, and robust multiview stereopsis. IEEE transactions on pattern analysis and machine intelligence 32, 1362-1376.

Gagliolo, S., Fagandini, R., Federici, B., Ferrando, I., Passoni, D., Pagliari, D., Pinto, L., and Sguerso, D., 2017. Use of UAS for the conservation of historical buildings in case of emergencies, Int. Arch. Photogramm. Remote Sens. Spatial Inf. Sci., XLII-5/W1, 81-88, doi.org/10.5194/isprs-archives-XLII-5W1-81-2017.

Harwin, S., Lucieer, A., 2012. Assessing the Accuracy of Georeferenced Point Clouds Produced via Multi-View Stereopsis from Unmanned Aerial Vehicle (UAV) Imagery. Remote Sensing 4, 1573-1599, https://doi.org/10.3390/rs4061573

Koci, J., Jarihani, B., Leon, J.X., Sidle, R.C., Wilkinson, S.N., Bartley, R., 2017. Assessment of UAV and Ground-Based Structure from Motion with Multi-View Stereo Photogrammetry in a Gullied Savanna Catchment. ISPRS International Journal of Geo-Information 6, 328. https://doi.org/10.3390/ijgi6110328

Kraus, K., 1994. Fotogrammetria Vol.1. Libreria universitaria Levrotto \& Bella, Torino.

LLC, A. (2016). Agisoft PhotoScan User Manual Professional Edition, Version 1.2. ed. St. Petersburg, Russia.

Lo Brutto, M., Garraffa, A., \& Meli, P., 2014. UAV platforms for cultural heritage survey: first results. ISPRS Annals of the Photogrammetry, Remote Sensing and Spatial Information Sciences, 5, 227-234.

Lowe, D. G. (2004). Distinctive image features from scaleinvariant keypoints. International journal of computer vision, 60(2), 91-110.

Lucarelli M., Laurini E., Rotilio M., De Berardinis P., 2018. Metodo BIM: gestione dei cantieri edilizi nei centri colpiti da calamità naturali, VI Edizione Convegno ReUso, Messina 1112-13 Ottobre 2018. Gangemi Editore, Roma, ISBN: 978-88492-3659-0

Meyer, D., Hess, M., Lo, E., Wittich, C. E., Hutchinson, T. C., \& Kuester, F., 2015, September. UAV-based post disaster assessment of cultural heritage sites following the 2014 South Napa Earthquake. In 2015 Digital Heritage (Vol. 2, pp. 421424). IEEE..

Nex, F., Remondino, F., 2014. UAV for 3D mapping applications: a review. Applied Geomatics 6, 1-15. 
Remondino, F., 2006. Detectors and descriptors for photogrammetric applications. International Archives of Photogrammetry, Remote Sensing and Spatial Information Sciences 36, 49-54.

Restas A., 2015. Drone Applications for Supporting Disaster Management. World Journal of Engineering and Technology, DOI: 10.4236/wjet.2015.33C047

Rotilio M., Laurini E., De Berardinis P., Cococcetta L., 2018. Progettare la cantierizzazione in un centro storico colpito dal sisma: un caso di studio, VI Edizione Convegno ReUso, Messina 11-12-13 Ottobre 2018, Gangemi Editore, Roma, ISBN: 978-88-492-3659-0

Sauerbier, M., Eisenbeiss, H., 2010. UAVs for the documentation of archaeological excavations. IAPRS\&SIS, Vol. 38(5), Newcastle upon Tyne, UK.

Themistocleous, K., Ioannides, M., Agapiou, A., Hadjimitsis, D. G., 2015. The methodology of documenting cultural heritage sites using photogrammetry, UAV, and 3D printing techniques: the case study of Asinou Church in Cyprus. In Third International Conference on Remote Sensing and Geoinformation of the Environment, pp. 953510-953510.

Triggs, B., McLauchlan, P.F., Hartley, R.I., Fitzgibbon, A.W., 1999. Bundle adjustment - a modern synthesis, in: International Workshop on Vision Algorithms. Springer, pp. 298-372.

Xu, Z.; Yang, J.; Peng, C.; Wu, Y.; Jiang, X.; Li, R.; Zheng, Y.; Gao, Y.; Liu, S.; Tian, B., 2014. Development of an UAS for post-earthquake disaster surveying and its application in Ms7.0 Lushan Earthquake, Sichuan, China. Computers \& Geosciences, v. 68 , p. $22-30$ 